\title{
Enhancing Student Engagement in a Blended Resident and Online Course Using Clickers and Embedded Questions
}

\author{
Anil K. Kulkarni ${ }^{1}$, Thomas Iwinski ${ }^{2}$ \\ ${ }^{1}$ The Pennsylvania State University, 334 Leonhard Building, University Park, PA 16802 USA, \\ ${ }^{2}$ The Pennsylvania State University, 301A Engineering Unit C, University Park, PA 16802 USA, \\ 'akk@psu.edu, ${ }^{2}$ tiwinski@engr.psu.edu
}

\begin{abstract}
This paper describes the use of Clickers (small, mobile phone like electronic devices) and embedded questions in streaming videos for the purpose of student engagement in a course that was taught with a blended delivery model in a live resident classroom and also delivered to distance education students online. In order to provide the ability for instructors to engage students in a rich interactive environment, a creative use of Clickers and embedded questions was developed for a course in Mechanical Engineering - ME 201: Introduction to Thermal Sciences at Penn State. Details of how Clicker devices and specially designed Clicker questions are used to receive feedback of students in a resident classroom are first presented, followed by details of using similar questions embedded in streaming videos for online delivery. The student feedback collection and its analysis for both resident and online courses is discussed. The study shows that such an approach makes creative use of the modern instructional technologies to enhance the teaching-learning process and improve the understanding of students.
\end{abstract}

Keywords - Clickers, Embedded Questions, Distance Education, Blended Delivery, Student Engagement, Streaming Video.

\footnotetext{
Anil K. Kulkarni

${ }^{1}$ The Pennsylvania State University, 334 Leonhard Building, University Park, PA 16802 USA,

1akk@psu.edu,
}

\section{Introduction}

Instructional technologies provide the ability for instructors to engage students in a rich interactive environment [1]. The creative use of these instructional technologies can also be employed to engage students in local resident classrooms as well as non-resident students studying online in the same course content. In an effort to serve students within a resident classroom delivery model and also reach distance education students online while limiting the effort required for course delivery, interaction and student assessment, we delivered a course, ME 201 Introduction to Thermal Science to a resident audience within a technology classroom that has the capability to perform Lecture Capture [2]. The instructor's content delivery to the resident students is recorded for the purpose of creating online streaming video versions of the lectures for distance education students who study the same course material online. One particular instructional technology employed in the classroom for student engagement is a Clicker student response system, which is transformed as embedded questions in the lecture videos.

\section{Using Clickers And Feedback In Resident Classroom Delivery}

\section{A. How Clickers Work}

Clickers are a technology that can be used to engage all students in classroom questions and polls [3]. In a traditional classroom setting when an 
instructor presents a question, only one or very few students have the opportunity to express their responses. This limits the feedback the instructor receives and his/her ability to gage the studentunderstanding of the concepts and ideas presented. One method to engage all students in responding to questions is for each student to use a clicker devise to respond to classroom questions. This technology allows all students to communicate and interact with the content in a way that keeps them engaged and paying attention and also provides the instructor valuable feedback about how well the students understand the material presented.

A typical system uses a handheld wireless remote control to transmit student responses to a receiver that tracks and records the interactions. The instructor can use this technology for simple polling or to engage in more in-depth questioning. The clicker responses can be tracked individually or collectively depending on the configuration and also how the instructor wants to use or display the student feedback. The clickers can be used to capture student responses anonymously if needed. The data gathered can be presented to the class to show the level of participation and understanding and also be saved and stored for later evaluation.

Most clickers use a simple multiple choice response option where the student is given a period of time to select an answer to a presented question. Each student has their own clicker response device that has a specific identity key that allows it to interact with the specific questions presented in the class. Clickers also have the ability to be programmed with multiple classroom codes so that they can be used with several courses. The questions can be predetermined and formal or they can be ad-hoc questions that emerge out of a classroom presentation or discussion.

B. Engaging all Students with Questions and Feedback

The instructor can organize the lecture content to use a variety of techniques to engage the students. Questions can be presented before the lecture begins to gather feedback on the student's prerequisite knowledge or to check attendance. These preliminary questions can seed the students' curiosity regarding the topic or concepts covered within the following lecture material.

Additional questions can be planned through the lecture to provide breaks or a change of pace to aid in keeping students alert and engaged. Questions presented at the end of the lecture can act as a review and summary of the material taught or might be designed as a lead-in to the next lecture to prime the students for new learning.

Formal questions from the ME 201 course are shown in Figure 1. It shows an example of a preliminary question regarding equilibrium.

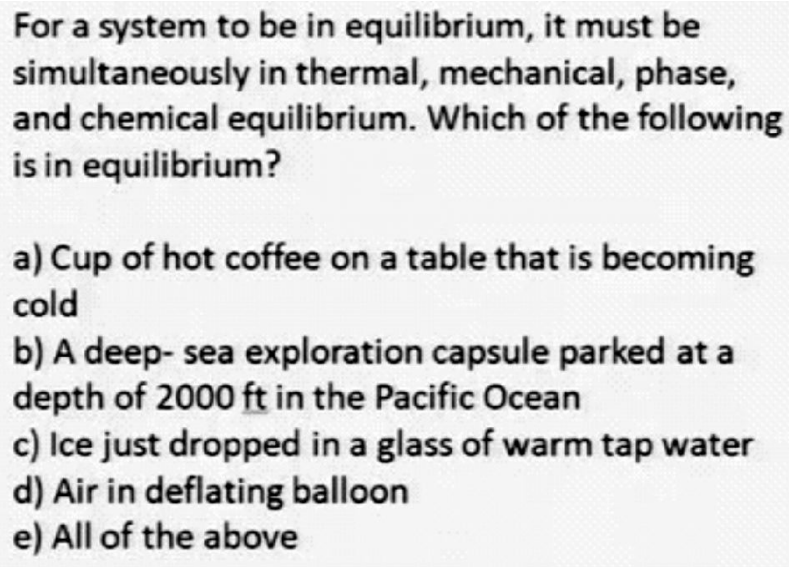

a) Cup of hot coffee on a table that is becoming cold

b) A deep- sea exploration capsule parked at a depth of $2000 \mathrm{ft}$ in the Pacific Ocean

c) Ice just dropped in a glass of warm tap water d) Air in deflating balloon

e) All of the above

Fig. 1. Example of a Formal Question presented for a Clicker Response.

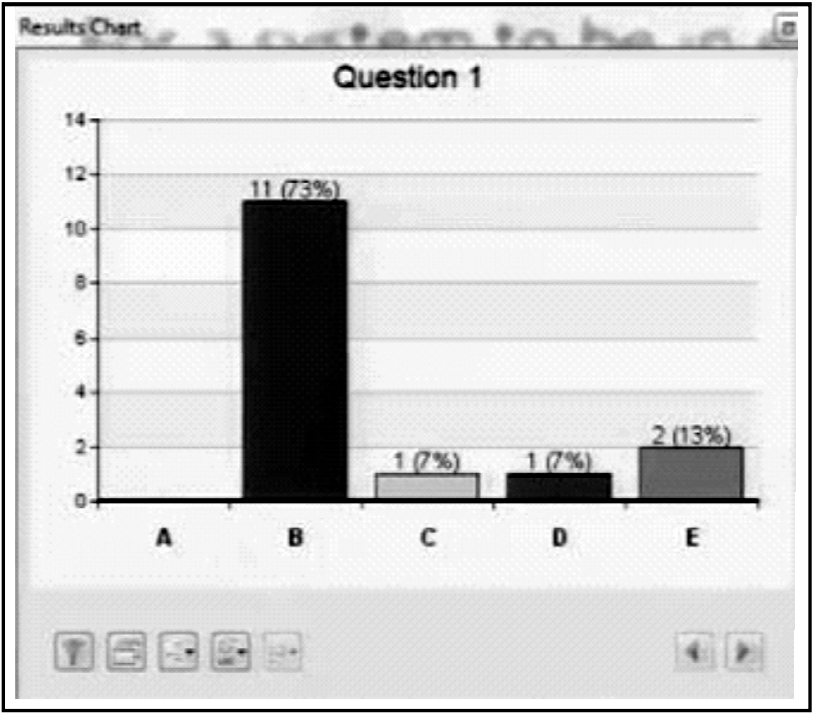

Fig. 2. Example of a Formal Question initial feedback from the Clicker response system.

The instructor then has a teachable moment to take the appropriate course of action in redirecting and guiding students to the correct understanding before revealing the correct answer to the students shown in 
Figure 3.

Figure 2 shows the initial un-scored results collected from the Clicker system. This is a way for the instructor to observe the range of responses and determine the depth of feedback or additional discussion that may be required for better understanding of the concepts presented.

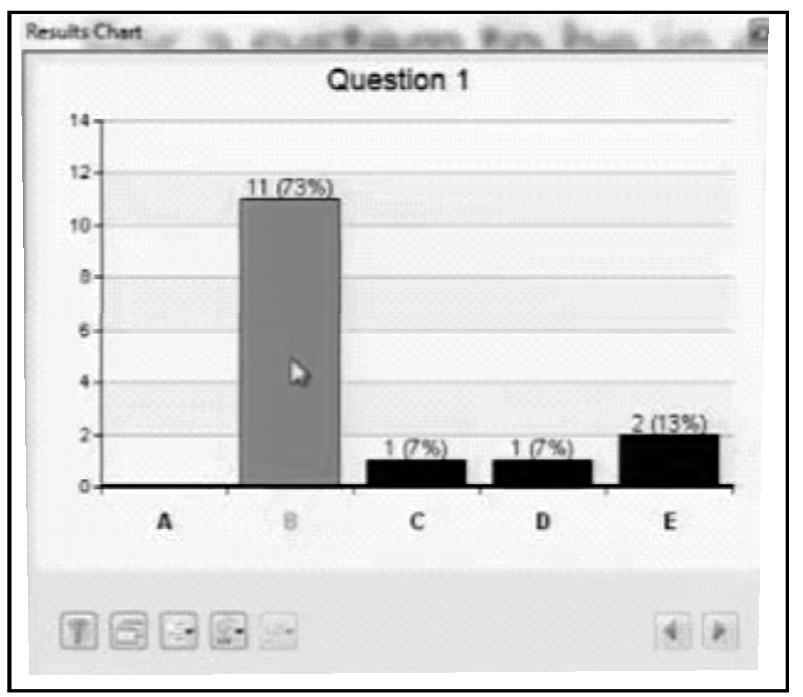

Fig. 3. Example of a Formal Question initial feedback from the Clicker response system.

Not all questions must be preformatted and arranged in the lecture materials beforehand. The Clicker response system is flexible in that as the lecture progresses and students present feedback in discussions and classroom activities, unplanned questions can be asked. The instructor can implement an unplanned informal question by simply writing them on the classroom whiteboard or tablet presentation display as seen in Figure 4.

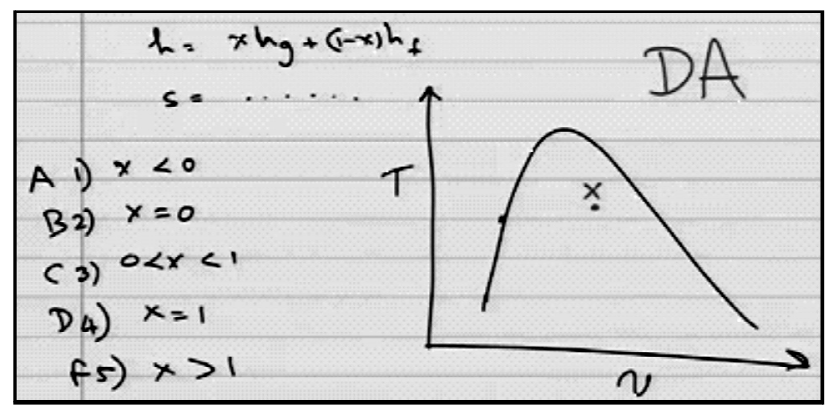

Fig. 4. Example of informal question presented from a tablet computer.
The results of the informal questions are collected and displayed in the same fashion as the formally composed questions shown previously.

All the while as these Clicker questions are presented and reviewed the entire lecture is being recorded with the Lecture Capture system for later use by distance education students that will engage the lecture material as a streaming video online. This is where the captured video needs to be modified in postproduction to include embedded questions that will stop the lecture and engage the students in the same fashion as those students in the resident classroom.

\section{Embedded Questions Within Streaming Video For Online Delivery Of Lecture Capture Content}

In an effort to provide a high degree of fidelity of the instructional delivery between the resident and online editions of the ME 201 course, we choose to recreate the experience of using the Clickers for the students that study online. This solution does not require any additional instructional content to be generated. It is accomplished by inserting an interactive question directly within the streaming video to recreate the experience of having the class stop to respond to a question. The exact same questions that were posed to the resident students are used in the embedded streaming video, so that when the video stream pauses to permit the student to respond, they are viewing the exact same experience and feedback that was delivered to the resident students.

\section{A. How Embedded Questions Work}

Students engaging in clicker questions in a classroom have a wireless remote control Clicker that allows the instructor to capture, display and record the students' responses. [4] Each physical clicker is registered to a student to identify the individual. To accomplish this same type of individual identification of distance education students viewing the lectures as streaming video online, we request the student identify themselves with their name and email address before they are allowed to view the lecture. Our system also provides the optional ability for the students to quickly review lecture videos without providing identification. But these instances are not tracked and students do not receive any participation credit if they choose to by-pass the embedded questions. See Figure 5 below for the authentication 
screen. Figure 6 shows the question presentation that students see when the video pauses for an embedded question.

\section{A first name, last name, and email address are required to take this quiz.}

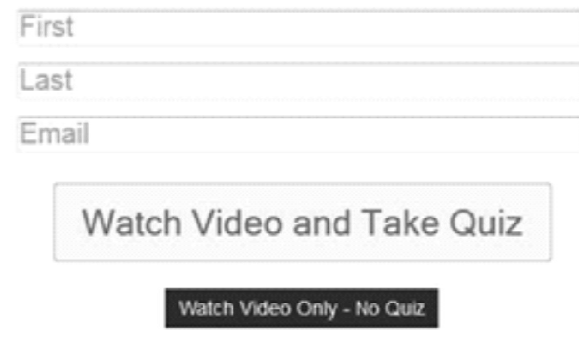

Fig. 5. This is the opening screen for the streaming video of the lecture capture that requiest students identify themselves to receive participation credit while viewing the leecture.

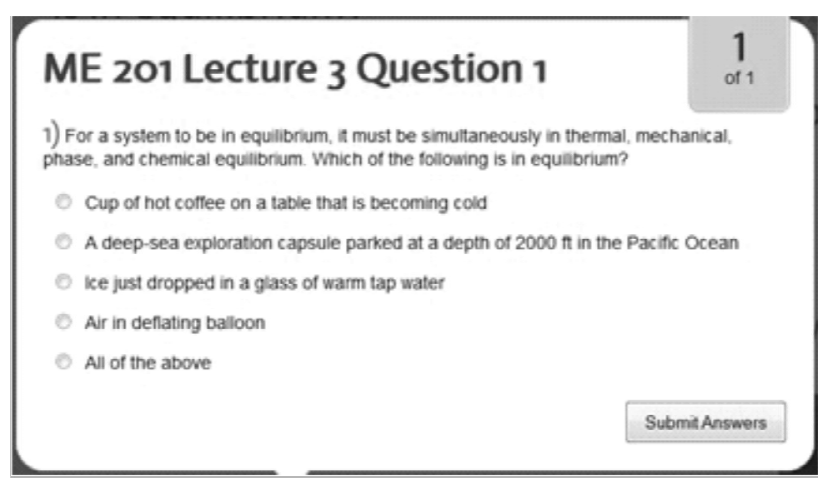

Fig. 6. Example of a Formal Question presented embedded within a streaming video of the captured lecture.

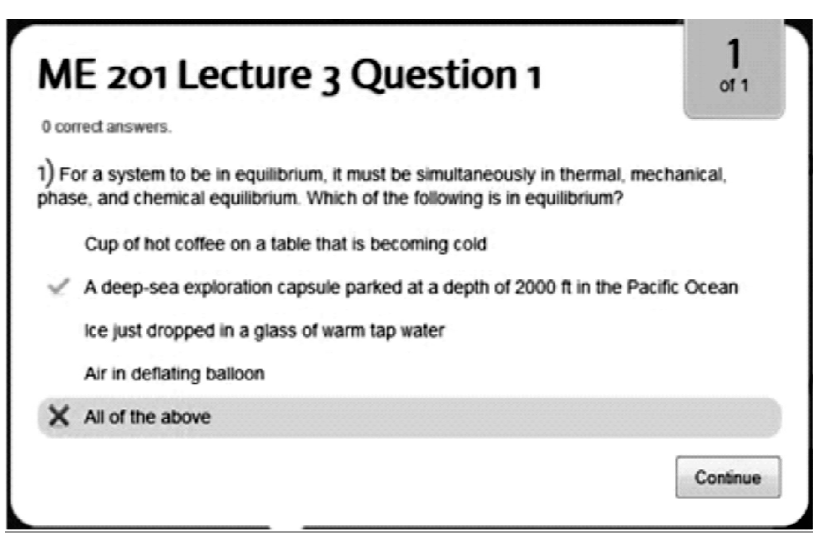

Below in Fugure 7 is an example of the feedback presented following an embedded question.
Fig. 7. Example of a Formal Question feedback embedded within a streaming video of the captured lecture.

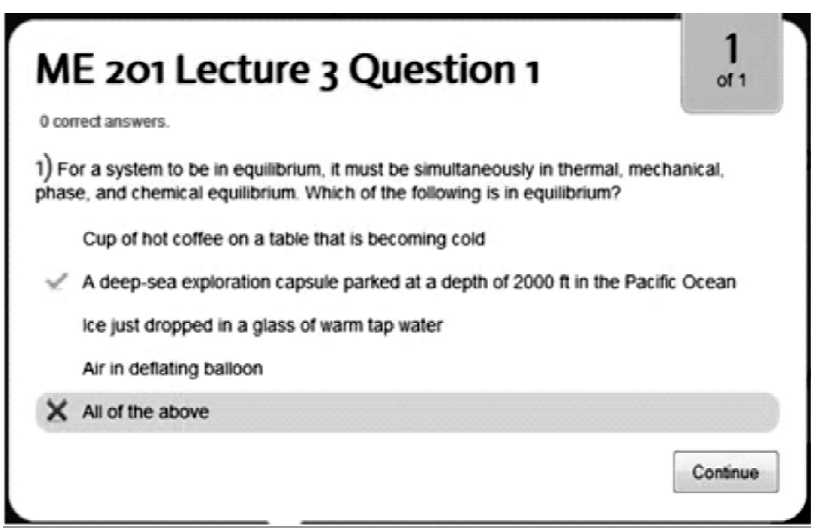

\section{B. Data From Clickers And Embedded Questions}

Data on student responses is collected by two systems. Resident student responses are gathered by the Clicker system and identified by specific handheld Clicker the student is using. The distance education students have their data collected online and are identified by the student's email address. The data is valuable not only for real-time feedback during instructional content delivery, but also has value for awarding participation credit to individual students. It is also great for performing post-course evaluation of content delivery objectives to help identify weakness in the course materials.

The data collection can be used for a variety of types of feedback including attendance, comprehension, review, assessment, sparking curiosity, mood and feelings, reactions, opinion polling/voting, sorting for teams/assignments. Most feedback results would be shared and immediately displayed to the students, some could be deliberately kept from public display for other purposes and later analysis.

The data is captured in real-time and structured for display and sorting. Each lecture can incorporate a variety of Clicker questions which are organized in a table shown in Figure 8. Custom rubrics can be applied for evaluation of the students' responses to assign points or grades. These grading policies need to be presented at the start of the course to inform students that their attendance and active participation are a requirement completing the course successfully.

The data collected by the Clicker system that is used in 
the resident instruction is quite detailed in the depth and breadth of the reports. Similarly, the data that gets collected from the embedded questions when delivering the recorded Lecture Capture streaming video to distance education students is organized and just as detailed. In both instances, the report data is organized by sorting the question sets by the lectures they are within, see Figure 10. Each lecture video captures and reports the data regarding student performance on the embedded questions within the streaming video.

\section{Student Voting Data Report}

Course Name : Intro to Thermal Science-ME 201-101

\begin{tabular}{|c|c|c|c|c|c|}
\hline \multicolumn{6}{|c|}{$\begin{array}{l}\text { Total Number of Sessions: } 28 \\
\text { Total Number of Students in Class: } 30 \\
\text { Total Number of Poinst for Term: } 260 \\
\text { hevi cumblathe student scores }\end{array}$} \\
\hline \multicolumn{6}{|c|}{$\begin{array}{l}\text { NW I Ho votes collected } \\
\text { Session Aversege = Colevistion based only on students who voted in that session. }\end{array}$} \\
\hline $\begin{array}{l}\text { Titiel } \\
\text { Session Date. }\end{array}$ & Report Links & $\begin{array}{l}\text { Mumber of Students } \\
\text { in Session }\end{array}$ & $\begin{array}{l}\text { Total Mumber of } \\
\text { Questions Asked }\end{array}$ & $\begin{array}{l}\text { Total Points } \\
\text { Avallable }\end{array}$ & Session Averape \\
\hline $\begin{array}{l}\text { Session } 1 \\
5 / 12 / 2013\end{array}$ & Student Respomes & 1 & 1 & 3 & 100.008 \\
\hline $\begin{array}{l}\text { Sension } 2 \\
5 / 12 / 2013\end{array}$ & Student Responses & 1 & 1 & 4 & $100.00 \%$ \\
\hline $\begin{array}{l}\text { Session } 3 \\
\text { s/13/2013 }\end{array}$ & Student Respones & 14 & 3 & 10 & $78.57 \%$ \\
\hline $\begin{array}{l}\text { Session } 4 \\
\text { S/14/2013 }\end{array}$ & Student Responses & 17 & 3 & 12 & 67.168 \\
\hline $\begin{array}{l}\text { Session } 5 \\
5 / 15 / 2013\end{array}$ & Student Ressonses & 17 & 4 & 15 & $85.88 \%$ \\
\hline $\begin{array}{l}\text { Session } 6 \\
\text { s/17/2013 }\end{array}$ & Student Rersonses & 23 & 6 & 23 & 93.958 \\
\hline $\begin{array}{l}\text { Session } 7 \\
\text { 5/21/2013 }\end{array}$ & Student Responses & 19 & 1 & 4 & 86.848 \\
\hline $\begin{array}{l}\text { Session } 8 \\
\text { S/22/2013 }\end{array}$ & Student Ressonses & 22 & 2 & 8 & 92.618 \\
\hline $\begin{array}{l}\text { Session } 9 \\
\text { s/23/2013 }\end{array}$ & Student Rerponses & 23 & 3 & 11 & 57.718 \\
\hline $\begin{array}{l}\text { Sersion } 10 \\
\text { s/24/2013 }\end{array}$ & Student Ressonses & 21 & 2 & 8 & $76.70 \mathrm{~m}$ \\
\hline
\end{tabular}

Fig. 8. Student data collected and sorted by the classroom Clicker system

Student Session 6/6/13 Report : Intro to Thermal Science-ME 201-101

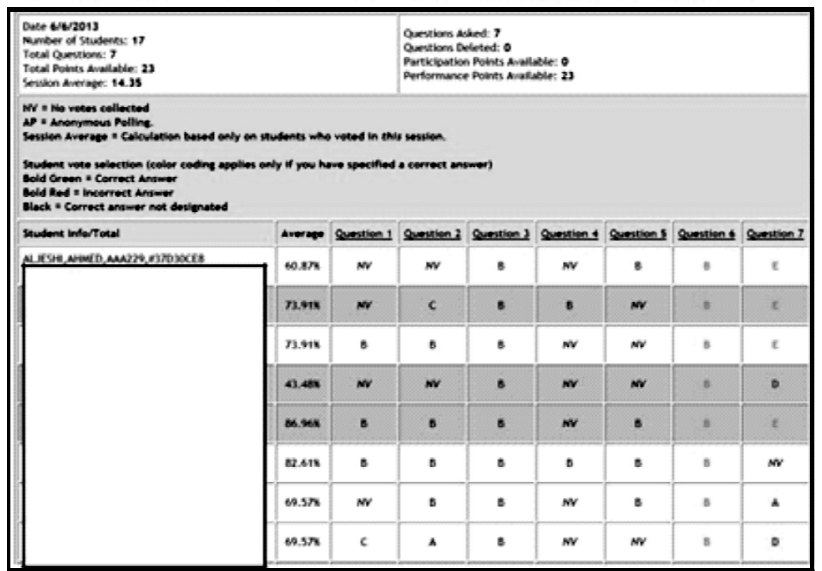

Fig. 9. Table of individual student performance collected by the Clicker system.

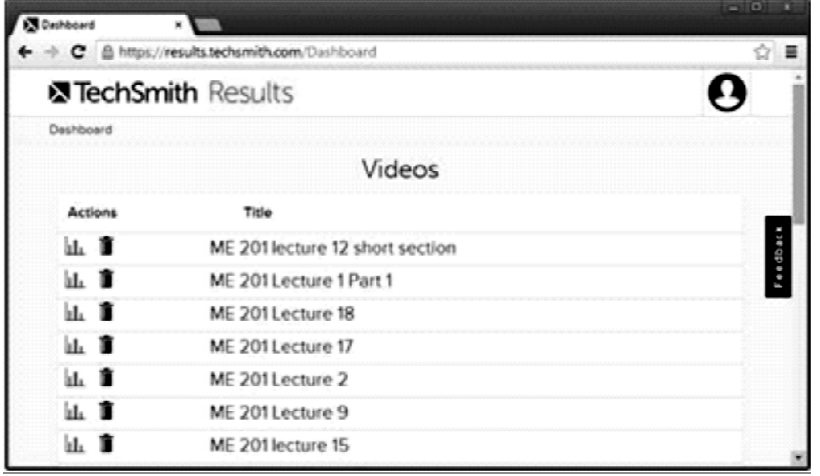

Fig. 10. Each lecture video captures and reports the data regarding student performance on the embedded questions within the online streaming video.

In addition to the data presented at the macro level of course engagement with clicker questions, additional detailed data regarding each individual question and individual student's performance in tracked and can be analyzed. See Figure 9 for an example.

In the same fashion as the resident instruction Clicker questions, the data gathered from the online embedded questions is further broken down into greater detail showing individual student performance on individual questions. This is shown in Figure 11.

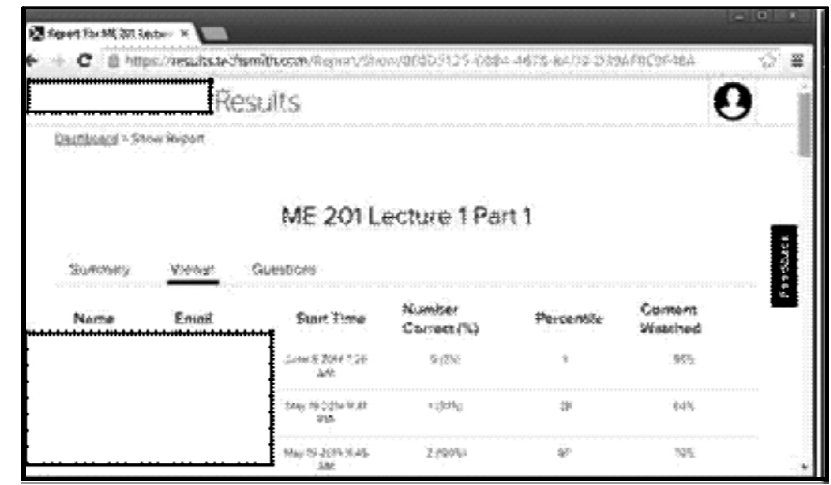

Fig. 11. Detailed data presented in a sorted table related to the students performance on Embedded Questions within the online streaming video.

An additional feature of the online system that tracks the Embedded Questions is a graphical display of the data to provide a quick view of student performance on each individual question. This is convenient in that the display allows the instructor to visualize the performance at a glance. The data recorded in the resident instruction Clicker system is available in tabular format and can be fashioned into a 
variety of charts and graphs, but doing so requires additional process steps and skill with spreadsheets and presentation software. Figure 12 shown the two types of graphs for an individual lecture with two questions.

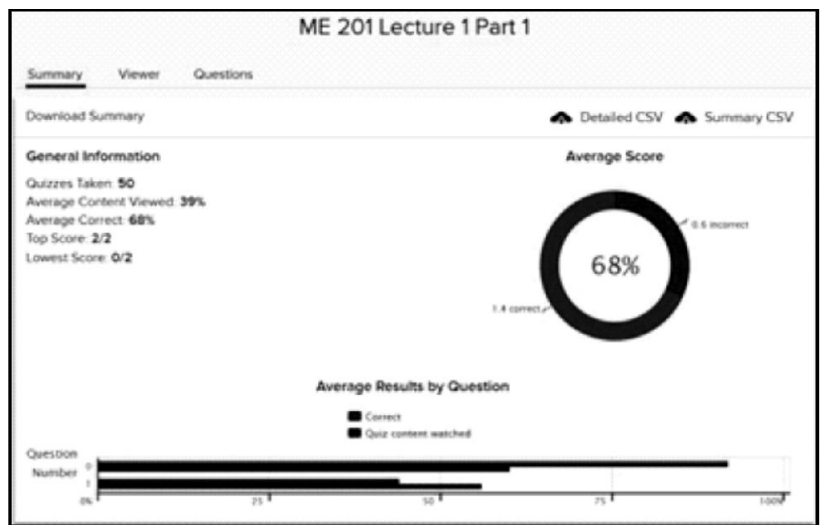

Fig. 12. Cumulative data presented in graphical form related to the students performance on embedded quiestions.

\section{Limitations and Design Concerns}

Clickers are not an excuse for neglecting personal interaction with students. Good instructional strategies need to incorporate methods for students to be personally engaged and interacting with the instructor and content, as well as with each other. Using Clickers provides a tool to extend the types of interactions and feedback processes that can make instructional environments meaningful and engaging to students.

\section{Summary And Conclusions}

In order to provide the ability for instructors to engage students in a rich interactive environment, a creative use of Clickers and embedded questions was developed for a course in Mechanical Engineering ME 201: Introduction to Thermal Sciences at Penn State. The instructor's content delivery to the resident students was recorded for the purpose of creating online streaming video versions of the lectures for distance education students who study the same course material online. The details of the instructional technologies for the use of Clickers and the embedded questions, how the delivery is setup, how and what type of the data is gathered, and how the data can be interpreted are discussed. It appears that such an approach makes creative use of the modern instructional technologies to enhance the teachinglearning process and improves the understanding of students.

\section{References}

[1]P. D. Chen, Lambert, A. D., and Guidry, K. R., Engaging online learners: The impact of Webbased learning technology on college student engagement, Vol 54, Issue 4, May 2010, Pages 1222-1232

[2] V. Fernandez, Simo, P., \& Sallan, J. M. (2009), Podcasting: A new technological tool to facilitate good practice in higher education Computers \& Education, 53, 385-392.

[3] J. E. Caldwell (2007), Clickers in the Large Classroom: Current Research and Best-Practice Tips, CBE Life Sci Educ 2007 6:9-20; doi:10.1187/cbe.06-12-0205

[4]F. G. Martin, Will Massive Open Online Courses Change How We Teach? Communications of the ACM, Vol. 55 No. 8 , 